Canadian Journal of Family and Youth, 14(2), 2022, pp. 172-176

ISSN 1718-9748@ University of Alberta

http://ejournals, library, ualberta.ca/index/php/cify

\title{
Chua, Amy. (2011). Battle Hymn of the Tiger Mother. New York: Penguin Publishing Group.
}

\author{
Reviewed by Zackary Osman
}

Amy Chua's, "Battle Hymn of the Tiger Mother", is a memoir about "a mom, her two kids, and her two dogs" (Chapter 1). Readers may believe that Chua's book is about how the Chinese parenting model may be superior to a Western model. However, it is better illustrated as "a clash of cultures, fleeting taste of glory, [and how Chua] was humbled by a thirteen-year-old" (Chapter 1). Furthermore, the title is a symbolic representation of Chua's struggle with the clash of cultures between her Chinese heritage and raising her children in western society. Also, Chua was born in the Chinese calendar year of the tiger which is a fearless and powerful animal that symbolizes respect and strength. Throughout the book, there are five prominent themes: (1) generational decline; (2) music; (3) a comparison between western and Chinese parenting; (4) differences between children as they are raised; and (5) Chua's re-evaluation of her belief systems.

Generations vary with regards to mentality and values. Chua feared a type of family decline which would be seen as a "common pattern among Chinese immigrants who came to the United States" if a longitudinal study were performed (Chapter 5). Said common pattern would illustrate how: Chua's parents' generation would be the strictest and hardest working individuals; Chua's generation would become professionals that will surpass their parents financially, and will not be as strict with their own children; finally, Chua's children's generation, that of Sophia and Lulu, will have many luxuries (e.g., expensive brand name clothing) and will feel like they can do 
as they please.

Chua has an "anti-decline campaign" out of fear and a desire to not raise her first born, Sophia, to be a "soft, entitled child" (Chapter 5), in an effort to keep her family from falling. Consequently, she wanted her children to be straight-A students, master the Chinese language, and do physical labour. Chua believed in having these skills to aid her children in learning respect, modesty, and humility. Also, Chua enrolled her children in classical music lessons because she insisted her children be more "[deep] and cultivated" (Chapter 5) than her parents were. To Chua, classical music was seen as the opposite of family decline, and the opposite of being lazy and spoiled. As a result, music plays a large role in the Chua family and is frequently mentioned in the book.

Sophia and Lulu are, without a doubt, very talented musicians. At first, Chua enrolled them in piano because "it is meaningful and highly difficult, with the depth of virtuosity" (Chapter 2). Sophia, in the beginning of her musical career, went through many piano instructors in order to find the best fit for her daughter. Chua is a firm believer of putting in the work to achieve a goal, but kids "do not want to work so it is crucial to override their preferences" (Chapter 6). To do that, Chua uses extreme measures, such as threatening to burn Sophia's stuffed animals, speaking in condescending tones, and making firm demands. Chua forces her children to practice every day, including weekends and holidays, so that they are ahead of schedule with hopes of performing in competitions to achieve the highest standing.

Lulu plays both the piano and violin because the violin is "much harder and virtuosic" (Chapter 8). Chua implemented the same procedures with Lulu as she did with Sophia; however, 
it is key to note that Lulu would purposely provoke her mother. Throughout the book, Chua demonstrates to the reader her tireless and hard efforts to support her children's musical endeavors while simultaneously juggling her work schedule as a law professor at Yale. As a result, the audience gets a clear illustration of the musical skills demonstrated by Chua's children. This is representative of the Chinese method of parenting described by Chua.

Chua makes frequent comparisons between Chinese and Western parenting. For example, on one hand, Chinese parents would not allow their children to "have sleepovers, playdates, watch TV, receive school grades lower than an A, and play instruments other than piano and violin" (Chapter 1). On the other hand, Western parents "believe in freedom and choice" (Chapter 34) and allow their children to make their own choices for their futures. Chua also makes a clear distinction between mindsets in each culture. For example, Western parents "are more concerned with the kids' psyches" (Chapter 10) whereas Chinese parents do not place much importance on this. Chua comparing and contrasting the two cultures continues throughout the book, which may be the result of a "combination of [Chua] having an immigrant family or having different cultural models" (Chapter 10).

In Chua's household, she mainly utilized the Chinese parenting model. She would oversee schoolwork and music endeavors, and spent more time with her children compared to her husband, Jed. Jed believes in strict parenting, but would sometimes remind Chua not to be so strict. Her methods do prove to be successful as her children became role models for other children. For example, people would ask if Chua has a secret parenting technique to produce such wellmannered children. However, one cannot expect that Chinese parenting can produce consistent 
results as not every child is the same.

At first, it was not "enjoyable for Sophia for having Chua as a mother" (Chapter 10). Chua's tiger mother characteristics made it especially difficult for Sophia initially because children typically do not want be doing work all the time at a young age. Despite the tough discipline, "they still worked together very well" (Chapter 6) with regards to academics and music. Despite Sophia being called "garbage when disrespectful" (Chapter 10) in front of others, Sophia would still respect her mother and not resent her. Lulu, on the other hand, is not quite the same.

Lulu is described as the more rebellious daughter. She is described as a "wild one with an angel's face" (Chapter 3), and there were some days where Lulu and Chua would engage in "all out nuclear warfare" (Chapter 3). For example, when Lulu was three years old, she would refuse to play a key on the piano, or would purposely not count when told to do so. Instead, she would "smash the piano keys harder and faster even when told to stop" (Chapter 3). As punishment, Chua forced Lulu to stand outside in the cold, and Lulu would not want to come back inside. From Lulu's early years to her teenage years, she would consistently defy her mother. Furthermore, Chua "sealed her fate" (Chapter 8) when she enrolled Lulu in violin lessons against her will. This is what is meant when Chua states, she "was humbled by a thirteen-year-old" (Chapter 1), which is a reference to Lulu. In addition, this is the point in time where Chua begins to re-evaluate her belief systems.

Throughout the book, Chua clearly conveys she has strict principles that her daughters will follow. Furthermore, one can observe that Chua knows how to rule the home with somewhat of 
an iron fist; however, as the book progresses, there is a gradual change in permissiveness. Chua would not allow Sophia to have a sleepover, but she gave in because Sophia begged. Ultimately, it turns out that the sleepover is not what Sophia thought it would be, and it was rather exhausting since she stayed up late with friends.

Lulu becomes tired with her mother's constant push to practice violin while dismissing Lulu's other interests, such as tennis. While Lulu enjoys practicing music, she simply "does not want to be intense about it" (Chapter 33). After many arguments between the two, Chua decides to let Lulu pursue her passion of tennis by putting her in lessons. Lulu, of course, is very content because she can practice tennis and violin without her mom forcing her to do so. It is at this point where Chua believes she should be more open-minded rather than demanding.

Chua's book has a diverse set of themes that others may relate to with respect to parenting. The book is not simply a how-to manual of the most effective childrearing practices, but rather a memoir of Chua's gradual change as a mother and as a person. Furthermore, there are strengths and weaknesses to Chua's methods. Chua does have incredible persistence and fortitude while raising her children; some may not agree with her methods, but she does get strong results. However, some may read this book without an open-minded approach and think her measures are rather extreme; also, as mentioned earlier, some may believe this book is a comparison between Chinese and Western parenting as it is frequently brought up. Aside from that, examples of disciplines that may benefit from the book are sociology, education, music, history, philosophy, and psychology. I thoroughly enjoyed "Battle Hymn of the Tiger mother" as it is humorous, engaging, deep, informative and easy to read. I would highly recommend it to readers of all ages and those who are interested in family studies. 